\title{
Lack of association of the MI29V polymorphism of the PRNP gene with pseudoexfoliation syndrome
}

\author{
This article was published in the following Dove Press journal: \\ Clinical Ophthalmology \\ 22 April 2016 \\ Number of times this article has been viewed
}

\author{
Marios P Giannakopoulos' \\ Anna G Antonacopoulou ${ }^{2}$ \\ Anastasia E Kottorou ${ }^{2}$ \\ Haralabos P Kalofonos ${ }^{2}$ \\ Sotirios P Gartaganis' \\ 'Department of Ophthalmology, \\ School of Medicine, ${ }^{2}$ Department \\ of Medicine, Molecular Oncology \\ Laboratory, Division of Oncology, \\ University of Patras, Rion, Greece
}

Correspondence: Marios P Giannakopoulos

Department of Ophthalmology,

School of Medicine, University of

Patras, 26504 Rion, Greece

Email gmariomail@gmail.com
Purpose: In this study we aimed to evaluate the polymorphism at codon 129 (M129V) of the PRNP gene as a secondary risk factor for pseudoexfoliation syndrome (PEX).

Methods: Two hundred and seventy-five unrelated subjects, including 156 patients with PEX and 119 unrelated control subjects, were recruited from the University Hospital of Patras, Greece. All patients and controls were of Caucasian or European ancestry. The PRNP M129V $(\mathrm{A} / \mathrm{G})$ single-nucleotide polymorphism was genotyped by real-time polymerase chain reactions. Association of the polymorphism with PEX was assessed using the two-sided Pearson's chi-squared or Fisher's exact test.

Result: No significant difference between patients and controls was observed in terms of frequencies of alleles and genotypes of the PRNP gene.

Conclusion: Polymorphism at M129V of the PRNP gene was evaluated as a secondary risk factor for developing PEX. Our results suggest that this PRNP gene polymorphism is not associated with PEX.

Keywords: pseudoexfoliation syndrome, polymorphism, M129V, PEX, protein folding disorders

\section{Introduction}

Pseudoexfoliation syndrome (PEX) is an age-related, generalized disorder of the extracellular matrix, which has a worldwide distribution and may affect up to $30 \%$ of people $>60$ years of age. ${ }^{1,2}$ PEX has been shown to be a systemic process, but it is especially associated with a broad spectrum of intraocular manifestations and complications. $^{3-8}$ The currently proposed pathogenetic concept of PEX describes the condition as a specific type of stress-induced elastosis, an elastic microfibrillopathy, associated with the excessive production of elastic microfibrils. ${ }^{9}$ The pathogenetic mechanism of the disease shares features with a group of clinically heterogeneous entities, collectively known as "protein-folding disorders". The better characterized is the group of amyloid disorders including Alzheimer's disease (AD) and Creutzfeldt-Jakob disease (CJD), and there is supporting evidence that PEX is associated with AD.

A key player in the pathogenesis of CJD is the prion protein (PRNP). The PRNP gene is located on chromosome 20p12.3 in humans and encodes a 253-amino acid protein. At position 129 of PRNP, a polymorphism has been noted, which results in the methionine (M) amino acid residue being replaced by a valine (V). This is the result of a single nucleotide change, ie, a single-nucleotide polymorphism or SNP, in the corresponding DNA molecule. This SNP, termed M129V, has a strong influence on susceptibility to sporadic CJD. ${ }^{10-12}$ Moreover, it has already been reported that in several European populations, AD is significantly associated with polymorphism in the PRNP codon $129 .{ }^{13-17}$

Assuming that PEX represents a conformational disorder that mimics AD at the molecular level, we reasoned that cellular PRNP may be involved in the pathogenic (c) ${ }_{\mathrm{BY}} \mathrm{NC}$ and incorporate the Creative Commons Attribution - Non Commercial (unported, v3.0) License (http://creativecommons.org/licenses/by-nc/3.0/). By accessing the work you hereby accept the Terms. Non-commercial uses of the work are permitted without any further permission from Dove Medical Press Limited, provided the work is properly attributed. For permission for commercial use of this work, please see paragraphs 4.2 and 5 of our Terms (https://www.dovepress.com/terms.php). 
mechanism of the disease. We investigated whether there is an association between the PRNP 129 polymorphism and the incidence of PEX disease in a Greek cohort.

\section{Materials and methods Study population}

Greek patients with clinically diagnosed PEX $(n=156)$ and healthy Greek control subjects $(n=119)$ were recruited from the University Hospital of Patras, Greece. Written informed consent was obtained from all subjects. The study protocol had the approval of the Rion University Hospital ethics committee, and it was performed according to the tenets of the Declaration of Helsinki.

All subjects underwent detailed ophthalmic examination by ophthalmologists, including slit lamp biomicroscopy examination, gonioscopy, dilated pupil examination of the lens, and funduscopy. Subjects with PEX were defined as those with clinical evidence of pseudoexfoliation in the pupil margin, anterior lens surface, or other anterior segment structures, with intraocular pressure $<21 \mathrm{mmHg}$ and no clinical evidence of glaucomatous optic neuropathy. Subjects with normal anterior segment and without clinical signs of PEX were recruited as control subjects.

\section{Genotyping}

Peripheral blood samples $(3 \mathrm{~mL})$ were collected from PEX patients and healthy controls by venipuncture. DNA was extracted from whole-blood samples using the QIAamp DNA blood mini kit (QIAGEN GmbH, Hilden, Germany).

The PRNP M129V (A/G) polymorphism was genotyped by real-time polymerase chain reaction (PCR) in an MX3000p PCR cycler (Stratagene, La Jolla, CA, USA), as previously described. ${ }^{18}$ Briefly, allele-specific primers were designed based on the sequence obtained from the SNP database (rs1799990) of the National Center for Biotechnology Information. A GC tail was added to the $5^{\prime}$-end of the G-specific primer, resulting in different product sizes depending on the allele. Thus, SYBR Green melting curve analysis revealed the genotypes of the subjects. The primers used were as follows: forward primer A (Met allele) 5'-GCATTGGCGGCTACA-3' forward primer G (Val allele) 5'-GCGGCGCGGCCCCCTTGGCGGCTTCG-3', and reverse primer 5'-CATAGTCACTGCCGAAATG-3'; these were synthesized by Metabion International (Martinsried, Germany). Reactions were performed in duplicate using the SYBR Green Master Mix (PrimerDesign, Southampton, UK) and included $300 \mathrm{nM}$ of each primer. The thermal profile used was as follows: one cycle of 10 minutes at $95^{\circ} \mathrm{C}$, followed by 40 cycles of 30 seconds at $95^{\circ} \mathrm{C}, 25$ seconds at $55^{\circ} \mathrm{C}$, and 20 seconds at $72^{\circ} \mathrm{C}$; and a melting curve between $70^{\circ} \mathrm{C}$ and $93^{\circ} \mathrm{C}$.

Representative genotypes were verified by sequencing. Briefly, a PCR product was obtained using the forward primer 5'-TCAGTGGAACAAGCCGAG-3' and the reverse primer 5'-GGGTAACGGTGCATGTTTTC-3'. PCR products were visualized by agarose gel electrophoresis, purified using the Nucleospin Extract II kit (Macherey-Nagel, Duren, Germany), and sequenced at CeMIA, Cellular and Molecular Immunological Applications (Larissa, Greece).

\section{Statistical analysis}

Hardy-Weinberg equilibrium of the genotypes was assessed with Pearson's goodness-of-fit chi-squared test. Hardy-Weinburg equilibrium was used to assess the stability of genetic variation from one generation to the next and, in this case, to ascertain that the sample group comprised of unrelated individuals. Statistical difference among the genotypic data was assessed using the two-sided Pearson's chi-squared test for parametric variables presented in tables with more than 2 rows or 2 columns or Fisher's exact test when analyzing $2 \times 2$ contingency tables. Binary logistic regression was used to assess risk for developing PEX. Statistical tests were performed using SPSS Statistics 17.0 (SPSS Inc., Chicago, IL, USA).

\section{Results}

One hundred and fifty-six Greek patients with PEX and 119 Greek healthy control subjects were recruited in the study. The patients with PEX had a mean age of 74.2 \pm 7.1 years (range: 60-88 years) and the normal control subjects had a mean age of $71.7 \pm 6.9$ years (range: $44-87$ years). Similarly, patients and healthy controls were matched for sex (Table 1).

\section{MI29V genotypes}

Genotypes of patients and controls conformed to expectations based on Hardy-Weinberg analysis (healthy controls: $P=0.68$; PEX subjects: $P=0.70)$. The majority of $P E X$ patients (48.1\%) were homozygous for the ancestral allele (AA)

Table I Demographic characteristics of PEX and control subjects

\begin{tabular}{|c|c|c|c|}
\hline Characteristics & $\begin{array}{l}\text { PEX subjects } \\
(n=156)\end{array}$ & $\begin{array}{l}\text { Control subjects } \\
(n=I 19)\end{array}$ & $P$-value \\
\hline Age, years & & & 0.793 \\
\hline Mean \pm SD & $73.57 \pm 8.05$ & $73.4 I \pm 7.57$ & \\
\hline Range & $56-88$ & $56-87$ & \\
\hline Sex, n (\%) & & & 0.616 \\
\hline Male & $92(59)$ & $65(55)$ & \\
\hline Female & $64(4 I)$ & $54(45)$ & \\
\hline
\end{tabular}

Note: $P$-value refers to the difference in age and sex between PEX and control subjects.

Abbreviation: PEX, pseudoexfoliation syndrome. 
Table 2 Genotype distributions and allele frequencies in PEX and control subjects

\begin{tabular}{lll}
\hline & $\begin{array}{l}\text { PEX subjects } \\
(\mathbf{n}=156)\end{array}$ & $\begin{array}{l}\text { Control subjects } \\
(\mathbf{n}=\mathbf{I} \text { | 9) }\end{array}$ \\
\hline MI29V genotype, $\mathbf{n}(\%)$ & & \\
AA & $75(48.1)$ & $59(49.6)$ \\
AG & $69(44.2)$ & $43(36.1)$ \\
GG & $12(7.7)$ & $17(14.3)$ \\
P-value & 0.142 & \\
AA + AG & $75(48.1)$ & $59(49.6)$ \\
GG & $81(51.9)$ & $60(50.4)$ \\
P-value & 0.809 & \\
Allele frequency & & \\
A & 0.676 & 0.702 \\
G & 0.324 & 0.298 \\
$P$-value & 0.227 & \\
\hline
\end{tabular}

Abbreviation: PEX, pseudoexfoliation syndrome.

which was similarly noted in the healthy control group (49.6\%) (Table 2). In the patient group, the AG genotype was more frequent compared to the healthy control group (44.2\% vs $36.1 \%)$. However, the importance of this difference was canceled out by the higher proportion of GG homozygotes in the healthy control group compared to the patient group ( $14.3 \%$ vs $7.7 \%$, respectively). Reflective of these results is the lack of difference in the allele frequency between the two groups (Table 2). To summarize, there was no significant difference in the genotype frequencies between healthy controls and patients with PEX irrespective of whether the three genotypes were assessed separately $(P=0.142)$ or grouped according to the presence or absence of the minor allele $(P=0.809)$ (Table 2). Furthermore, PRNP M129V is not a risk factor for developing PEX (odds ratio: 0.893, 95\% confidence interval: $0.625-1.275, P=0.532$ ).

\section{Discussion}

PEX is an age-related, generalized disorder of the extracellular matrix characterized by the production and progressive accumulation of a fibrillar extracellular material in many ocular tissues. ${ }^{19}$ Despite extensive research, the pathogenesis of PEX syndrome remains obscure and the pathological changes similar to those in the eye have been identified in many visceral organs such as lung, heart, gallbladder, brain, as well as in the skin. Although, the exact composition of the abnormal extracellular material as well as the mechanisms responsible for its excessive production and accumulation still remain unknown, the concept of an elastotic process has recently been established. Molecular biological and biochemical data support the pathogenetic concept of PEX syndrome as a type of stress-induced elastic fibrillopathy. The etiopathogenesis involves genetic and non- genetic factors and resembles the group of amyloid disorders such as $\mathrm{AD}$ and CJD. PEX plays an etiologic role in open-angle glaucoma, angle-closure glaucoma, cataract, and retinal vein occlusion and has been associated with an increasing number of systemic disorders, including vascular disease, hearing loss, and $\mathrm{AD}{ }^{20-23}$

Previous studies have demonstrated that peptides related to $\mathrm{AD}$ were found more often in the aqueous humor of eyes with PEX and that PEX was significantly increased in the whole group of patients with $\mathrm{AD}$, as compared to the age-matched population, in a survey. ${ }^{24,25}$ Additionally, AD-related proteins such as Abeta peptide and the serine proteinase inhibitors alpha-1-antitrypsin and alpha-1antichymotrypsin are present in the aqueous humor of PEX patients. ${ }^{24,25} \mathrm{~A}$ polymorphism of apolipoprotein $\mathrm{E}$, which is involved in many amyloid disorders such as $\mathrm{AD}$, promoting the aggregation of amyloidogenic proteins into the $\beta$-pleated sheet conformation, was also found to be greatly associated with PEX development. ${ }^{26}$ Both AD and CJD show common characteristics in the pathogenesis of neurodegeneration in terms of the aggregation of abnormally folded proteins in neural tissues. ${ }^{27}$ In $\mathrm{AD}$, amyloid proteins accumulate extracellularly, while in CJD, an isoform $\mathrm{PrP}^{\mathrm{res}}$ of the prion protein $\mathrm{PrP}^{\mathrm{c}}$ forms aggregates, also extracellularly, forming amyloid-like plaques in neural tissues. It is also of interest that in CJD patients accumulations of both these types of proteins have been noted in neural tissue specimens, raising the possibility of common pathogenetic mechanisms existing between $\mathrm{AD}$ and CJD. ${ }^{28-30}$

The methionine/valine polymorphism at codon 129 within the PRNP gene is a known risk factor for CJD, while it is not clear whether the same is true for AD. There are some reports about the effects of this polymorphism on the risk of $\mathrm{AD}$, but with dubious results, ${ }^{28}$ although it is certain that it plays a role in cognitive performances. ${ }^{20}$

Polymorphism of the PRNP gene at codon 129 has been associated with neurodegenerative disease development and severity, while no information is available regarding its role in the incidence of PEX. To elucidate a possible effect of the PRNP gene polymorphism as a risk factor for PEX, we examined the distribution of M129V in 156 Greek individuals diagnosed with the disease and in 119 normal controls. No significant difference between patients and controls was observed in terms of the frequencies of alleles and genotypes of $P R N P$.

Our result showed that polymorphism of the $P R N P$ gene at codon 129 is not associated with PEX as no significant difference between patients and controls was observed in the frequencies of alleles and genotypes of $P R N P$. Despite the fact that this is a known risk factor for CJD, not all of these protein-folding disorders share the same molecular 
pathogenetic mechanisms. In $\mathrm{AD}$, where there is a possible association with PEX, the effect of PRNP 129 polymorphism is controversial. In addition, a polymorphism of the LOXL1 gene, which is strongly associated with PEX, is lacking in AD. ${ }^{31}$ Therefore, several gene polymorphisms influence a range of diseases of similar groups in different ways, and their effects do not always reflect the molecular mechanisms of the disease.

\section{Disclosure}

The authors report no conflicts of interest in this work.

\section{References}

1. Anastasopoulos E, Founti P, Topouzis F. Update on pseudoexfoliation syndrome pathogenesis and associations with intraocular pressure, glaucoma and systemic diseases. Curr Opin Ophthalmol. 2015;26(2): $82-89$.

2. Forsius H, Forsman E, Fellman J, Eriksson AW. Exfoliation syndrome: frequency, gender distribution and association with climatically induced alterations of the cornea and conjunctiva. Acta Ophthalmol Scand.2002; 80(5):478-484.

3. Ritch R, Schlötzer-Schrehardt U. Exfoliation syndrome. Surv Ophthalmol. 2001;45(4):265-315.

4. Yazdani S, Tousi A, Pakravan M, Faghihi A. Sensorineural hearing loss in pseudoexfoliation syndrome. Ophthalmology. 2008;5(3):393-396.

5. Schlotzer-Schrehardt U, Naumann GOH. Ocular and systemic pseudoexfoliation syndrome. Am J Ophthalmol. 2006;141(5):921-937.

6. Papadopoulos TA, Naxakis SS, Charalabopoulou M, Vathylakis I, Goumas PD, Gartaganis SP. Exfoliation syndrome related to sensorineural hearing loss. Clin Experiment Ophthalmol. 2010;38(5):456-461.

7. Schumacher S, Schlötzer-Schrehardt U, Martus P, Lang W, Naumann GOH. Pseudoexfoliation syndrome and aneurysms of the abdominal aorta. Lancet. 2001;357(9253):359-360.

8. Andrikopoulos GK, Alexopoulos DK, Gartaganis SP. Pseudoexfoliation syndrome and cardiovascular diseases. World J Cardiol. 2014;6(8): $847-854$.

9. Tousseyn T, Bajsarowicz K, Sánchez H, et al. Prion disease induces alzheimer disease-like neuropathologic changes. J Neuropathol Exp Neurol. 2015;74(9):873-888.

10. Nyström S, Mishra R, Hornemann S, Aguzzi A, Nilsson KP, Hammarström P. Multiple substitutions of methionine 129 in human prion protein reveal its importance in the amyloid fibrillation pathway. J Biol Chem. 2012;287(31):25975-25984.

11. Jeong BH, Lee KH, Kim NH, et al. Association of sporadic CreutzfeldtJakob disease with homozygous genotypes at PRNP codons 129 and 219 in the Korean population. Neurogenetics. 2005;6(4):229-232.

12. Sanchez-Juan P, Bishop MT, Croes EA, et al. A polymorphism in the regulatory region of PRNP is associated with increased risk of sporadic Creutzfeldt-Jakob disease. BMC Med Genet. 2011;12:73.

13. Pimentel LF, Gomes da Cunha JE, Morelato RL, de Paula F, de Oliveira JR. Epidemiological genetics and meta-analysis of a polymorphism at codon 129 of the PRNP gene in Alzheimer's disease in Brazil. Neurol Res. 2014; 36(9):775-778.

Clinical Ophthalmology

\section{Publish your work in this journal}

Clinical Ophthalmology is an international, peer-reviewed journal covering all subspecialties within ophthalmology. Key topics include: Optometry; Visual science; Pharmacology and drug therapy in eye diseases; Basic Sciences; Primary and Secondary eye care; Patient Safety and Quality of Care Improvements. This journal is indexed on Submit your manuscript here: http://www.dovepress.com/clinical-ophthalmology-journal
14. Gacia M, Safranow K, Styczyñska M, et al. Prion protein gene M129 allele is a risk factor for Alzheimer's disease. J Neural Transm. 2006; 113(11):1747-1751.

15. He J, Li X, Yang J, et al. The association between the methionine/valine $(\mathrm{M} / \mathrm{V})$ polymorphism (rs1799990) in the PRNP gene and the risk of Alzheimer disease: an update by meta-analysis. J Neurol Sci. 2013; 326(1-2):89-95.

16. Riemenschneider M, Klopp N, Xiang W, et al. Prion protein codon 129 polymorphism and risk of Alzheimer disease. Neurology. 2004;63(2): 364-366.

17. Mead S. Prion disease genetics. Eur J Hum Genet. 2006;14(3): 273-281.

18. Antonacopoulou AG, Palli M, Marousi S, et al. Prion protein expression and the M129V polymorphism of the PRNP gene in patients with colorectal cancer. Mol Carcinog. 2010;49(7):693-699.

19. Ritch R. Ocular and systemic manifestations of exfoliation syndrome. J Glaucoma. 2014;23(8 suppl 1):S1-S8.

20. Linnér E, Popovic V, Gottfries CG, Jonsson M, Sjogren M, Wallin A. The exfoliation syndrome in cognitive impairment of cerebrovascular or Alzheimer's type. Acta Ophthalmol Scand. 2001;79(3):283-285.

21. Anastasopoulos E, Coleman AL, Wilson MR, et al. Association of LOXL1 polymorphisms with pseudoexfoliation, glaucoma, intraocular pressure, and systemic diseases in a Greek population. The Thessaloniki eye study. Invest Ophthalmol Vis Sci. 2014;55(7):4238-4243.

22. Holló G. Exfoliation syndrome and systemic cardiovascular diseases. J Glaucoma. 2014;23(8 suppl 1):S9-S11.

23. Bettis DI, Allingham RR, Wirostko BM. Systemic diseases associated with exfoliation syndrome. Int Ophthalmol Clin. 2014;54(4):15-28.

24. Berlau J, Lorenz P, Beck R, et al. Analysis of aqueous humour proteins of eyes with and without pseudoexfoliation syndrome. Graefes Arch Clin Exp Ophthalmol. 2001;239(10):743-746.

25. Janciauskiene S, Krakau T. Alzheimer's peptide: a possible link between glaucoma, exfoliation syndrome and Alzheimer's disease. Acta Ophthalmol Scand. 2001;79(3):328-329.

26. Krumbiegel M, Pasutto F, Mardin CY, et al. Apolipoprotein E genotypes in pseudoexfoliation syndrome and pseudoexfoliation glaucoma. J Glaucoma. 2010;19(8):561-565.

27. Aguzzi A, Haass C. Games played by rogue proteins in prion disorders and Alzheimer's disease. Science. 2003;302(5646):814-818.

28. Dermaut B, Croes EA, Rademakers R, et al. PRNP Val129 homozygosity increases risk for early-onset Alzheimer's disease. Ann Neurol. 2003;53(3):409-412.

29. Calero O, Bullido MJ, Clarimón J, et al. Genetic cross-interaction between APOE and PRNP in sporadic Alzheimer's and CreutzfeldtJakob diseases. PLoS One. 2011;6(7):e22090.

30. Muñoz-Nieto M, Ramonet N, López-Gastón JI, et al. A novel mutation I215V in the PRNP gene associated with Creutzfeldt-Jakob and Alzheimer's diseases in three patients with divergent clinical phenotypes. J Neurol. 2013;260(1):77-84.

31. Abramsson A, Landgren S, Zetterberg M, et al. No association of LOXL1 gene polymorphisms with Alzheimer's disease. Neuromolecular Med. 2011;13(2):160-166.

PubMed Central and CAS, and is the official journal of The Society of Clinical Ophthalmology (SCO). The manuscript management system is completely online and includes a very quick and fair peer-review system, which is all easy to use. Visit http://www.dovepress.com/ testimonials.php to read real quotes from published authors. 